\title{
Implementation of energy efficiency measures in compressed air systems: barriers, drivers and non-energy benefits
}

Therese Nehler, Ricardo Parra and Patrik Thollander

The self-archived postprint version of this journal article is available at Linköping University Institutional Repository (DiVA):

http:/ / urn.kb.se/ resolve?urn=urn:nbn:se:liu:diva-148368

N.B.: When citing this work, cite the original publication.

The original publication is available at www.springerlink.com:

Nehler, T., Parra, R., Thollander, P., (2018), Implementation of energy efficiency measures in compressed air systems: barriers, drivers and non-energy benefits, Energy Efficiency, 11(5), 1281-1302. https:/ / doi.org/ 10.1007/s12053-018-9647-3

Original publication available at:

https:/ / doi.org/ 10.1007/ s12053-018-9647-3

Copyright: Springer Verlag (Germany)

http:// www.springerlink.com/ ?MUD=MP 


\title{
Implementation of energy efficiency measures in compressed air systems: Barriers, drivers \& non-energy benefits
}

\author{
Therese Nehlera,*, Ricardo Parrab, Patrik Thollandera \\ aDivision of Energy Systems, Linköping University, Sweden. *Corresponding author. Tel.: +4613282084. \\ E-mail address: therese.nehler@liu.se \\ bConsultora Crowsnest, Chile.
}

\begin{abstract}
Increased global competition and resource scarcity drives industrial companies to cut costs. Energy can be a significant component of such cuts, particularly for energy-intensive companies. Improving energy efficiency in industry is complex, as it pertains to various energy-using processes that are heavily intertwined. One such process is the compressed air system (CAS), which is used in most industrial companies worldwide. Since energy efficiency improvement measures for various types of energy-using processes differ, technology-specific measures might encounter different barriers to and drivers for energy efficiency. The same applies to the nonenergy benefits (NEBs) related to energy efficiency improvement measures; since measures vary between various energy-using processes, the perceived NEBs might be different as well. The aim of this paper is to study the barriers to, drivers for and NEBs of CAS energy efficiency improvement measures from the perspectives of three actors. Carried out as an interview study combined with a questionnaire, the paper merges the perspectives of users, audit experts and suppliers of CASs. The results showed that the major barriers are related to the investment, or are of an organisational character, and that organisational and economic factors seemed to be important for making positive decisions on energy efficiency investments and measures in CASs. Major NEBs for CASs include productivity gains and the avoidance of capital expenditures. The results of this study also address the importance of having a comprehensive approach to recognise additional effects of energy efficiency improvements in CASs.
\end{abstract}

Keywords: Compressed air systems, industrial energy efficiency, barriers, drivers, energy efficiency measures, non-energy benefits

\section{Acknowledgements}

This paper has been carried out as a part of the research project Excen-e (improved industrial energy efficiency among SMEs in Ostergotland). The research project is partly financed by the European Commission within the European Regional Development Fund, administrated by the Swedish Agency for Economic and Regional Growth, and also partly financed by Linkoping University. We kindly thank the funding bodies for their financial support. Furthermore, the authors kindly thank the respondents for freely giving their time to answer our questions. 


\section{Introduction}

Industrial energy efficiency is viewed as necessary for sustainability due to growing concerns over the environment and the scarcity of resources (IPCC 2014). Increased global competition also drives industrial companies to strive for efficiency, and since most of the processes in an industrial company are related to energy, continuous improvements in energy efficiency will thus contribute to increasing a company's overall efficiency (Johansson et al. 2011). The generation of compressed air is one energy-using process that is used in various applications in most industrial companies worldwide. A compressed air system (CAS) often supports many production processes (e.g. assembling, clamping, cushioning, processing, cleaning and drying) in a company (e.g. Björk et al. 2003). Hence, most CASs are tailored to fit a specific company and its related production. However, the measures for improving energy efficiency in CAS generally apply to most systems and companies.

In their review of energy use in relation to compressed air, Saidur et al. (2010) conclude that energy efficiency improvement measures in CASs have considerable potential, particularly in relation to sealing leaks. Despite the existing energy efficiency potential in industry (EC 2011), improvement measures are not always implemented, even when they are cost-effective, which is often explained by the presence of barriers (e.g. Sorrell et al. 2004; Trianni et al. 2012). Therefore, a gap appears to exist between the theory of energy efficiency and what is actually achieved. However, with a few exceptions (e.g. Cagno and Trianni 2014), previous research on barriers to energy efficiency has treated energy efficiency improvement measures as a single entity to be studied at the company level. Thus, the number of scientific studies on barriers to energy efficiency improvement measures for specific energy-using processes, such as the generation and use of compressed air, are limited. Cagno and Trianni's (2014) study is one of the few to investigate barriers to specific industrial energy efficiency measures. Cagno and Trianni (2014) conclude that there are great differences in the barriers to different types of energy efficiency measures. This highlights the importance of further studies of such barriers, as improved knowledge might contribute to decision making regarding energy efficiency measures and investments, which in turn could help improve industrial energy efficiency.

Studies on the driving forces of industrial energy efficiency are of interest since they might provide a means to overcome the barriers. Empirical studies have identified important drivers for measures to improve energy efficiency (e.g. Apeaning and Thollander 2013; Cagno and Trianni 2013; Hasanbeigi et al. 2010; Thollander and Ottosson 2008; Rohdin et al. 2007), but studies on drivers for specific energy efficiency measures are scarce. Due to the paucity of research in this area, studying such drivers (for instance, energy efficiency improvement measures for CASs) would be useful and could contribute to overcoming the specific barriers.

The concept of non-energy benefits (NEBs) and their magnitude could positively affect the adoption rate of energy efficiency improvement measures (Fleiter et al. 2012). NEBs refer to the side effects of energy efficiency improvement measures, which go beyond the energy savings related to the measures. Studies have shown that there are benefits to investing in energy efficiency and that they can be substantial, particularly if the NEBs are quantified and monetised (e.g. Pye and McKane 2000; Worrell et al. 2003). In addition, NEBs might be a means to overcome barriers to energy efficiency, or they might act as drivers for energy efficiency. Hence, there is also a need to investigate the NEBs for specific energy efficiency improvement measures.

Studies on the characteristics of energy efficiency measures also underline the need to study the technology-specific barriers and drivers as well as the NEBs of specific energy efficiency improvement measures (Fleiter et al. 2012; Trianni et al. 2014). Since characteristics may differ, technology-specific measures might face different barriers to and drivers for energy efficiency, which will affect investment decisions accordingly. The same applies to the NEBs related to energy efficiency improvement measures. Studying the barriers, drivers and NEBs in relation to energy efficiency improvement measures for specific industrial processes, such as CASs, should thus be of interest to academics, as well as practitioners and policymakers. 
The aim of this paper is to study the barriers to, drivers for and NEBs of CAS energy efficiency improvement measures from the perspectives of users, auditors and suppliers. This is addressed through the following three research questions:

- What are the barriers to the implementation of energy efficiency measures in CASs?

- What are the drivers for the implementation of energy efficiency measures in CASs?

- What are the NEBs of implemented energy efficiency measures in CASs?

This paper starts by giving an overview of industrial CASs and continues with a brief presentation of the barriers to and drivers for energy efficiency. This is followed by an outline of the role of NEBs with regard to energy efficiency, barriers and drivers. Next, this paper's methodological approach is described, followed by a presentation and discussion of the findings. In the last section, concluding remarks are given.

\section{Compressed air systems}

Compressed air is a widely used application that supports many industrial processes, depending on the specific needs dictated by the type of production in the industrial company. Compressed air equipment is viewed as both practical and simple to use; furthermore, it is often regarded as inexpensive. However, the efficiency of a CAS is often low due to for example leaks in the system (e.g. Björk et al. 2003). Since CASs are often heavily intertwined with a company's industrial processes, thereby resulting in a complex system, efficiency and energy efficiency opportunities are challenged in various ways.

In this section, a brief overview of a CAS and the process of generating compressed air will be provided. Thereafter, ways to improve energy efficiency in a CAS will be described.

\subsection{Compressed air - A brief overview of the system}

Industrial production is comprised of various processes that require different kinds of movements, transport and positioning, as well as steps like assembling, cushioning, processing, cleaning, drying, dosage and the operation of valves (Björk et al. 2003). Compressed air and its associated applications are commonly used to support these movements and steps.

The process in a CAS starts with the generation of compressed air (supply), which is then transported (distribution) to the end-use location (demand). CASs consist of various sub-systems and related components, and they can be divided into the supply side and the demand side (CEATI 2007). The supply side consists of parts such as the air inlet, motor, compressor, after-cooler, treatment, controls and storage (primary), while the demand side includes distribution, storage (secondary) and end-use equipment (CEATI 2007). In Figure 1, the main features of a CAS and the interrelations between the sub-parts are illustrated.

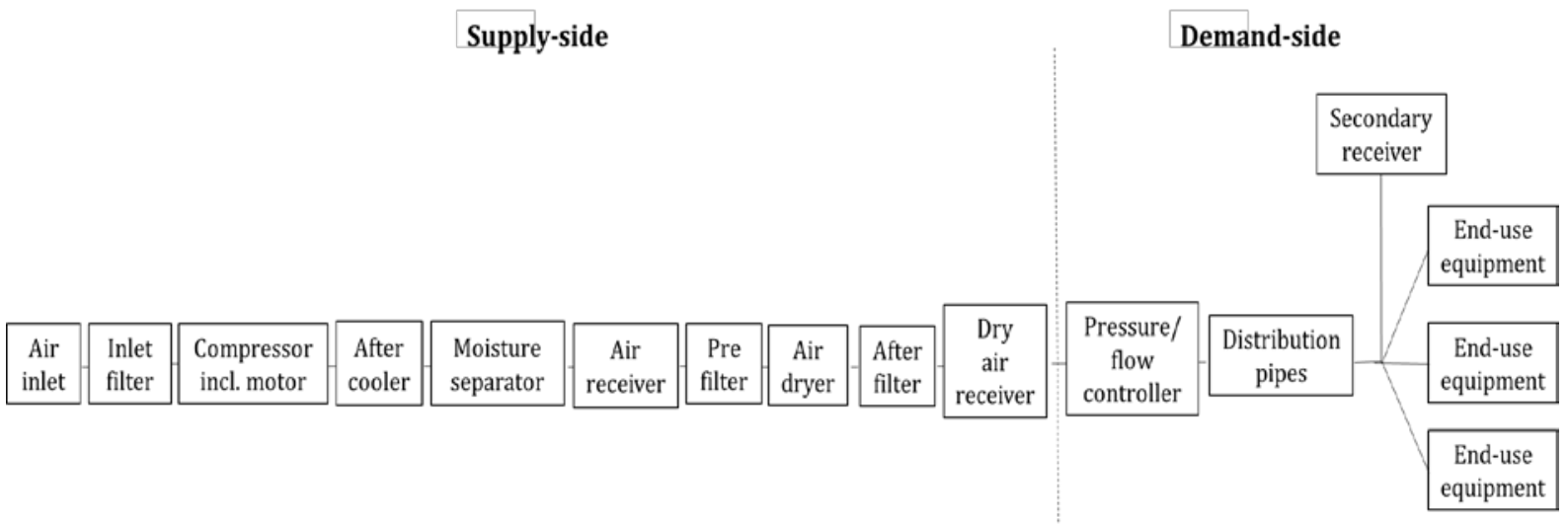


Figure 1. A CAS and related sub-parts divided according to supply and demand sides (Atlas Copco 2009; CEATI 2007; DOE 2003).

The compressor is most often driven by an electric motor that can be integrated into the compressor unit or installed separately. There are two main types of air compressors in CASs: displacement and dynamic. Atmospheric air contains water vapour, and since the concentration of water in air increases in higher temperatures and under higher pressures, the amount of water vapour is a parameter that must be considered in all CASs. Moisture can cause problems in the compressed air equipment, for instance, if water precipitates in the piping. Hence, the air has to be dried, and this is done by using an after-cooler and drying equipment. The compression of air also generates heat, which requires cooling of the air after the compression stage. The compressed air should be of the right quality, as specified by the application, and this depends on the role the compressed air has within the company's processes. As described above, compressed air can contain water (drops or vapour), but also oil (drops or aerosols) and particles (e.g. dust and microorganisms). The oil content of compressed air depends on the type of compressor, that is, whether or not it is oil-lubricated, and the downstream filtration used in the system. In oillubricated compressors, the compressed air will contain oil, with the quantity depending on the type of compressor as well as its design, age and condition. The quality of the air depends on the specified quality class of the air, and the type of filters is determined according to these requirements. To move the compressed air to the end-use equipment, a distribution system is required. Further, one or more extra air receivers can be installed in the system as buffers of compressed air.

\subsection{Energy efficiency improvement measures for compressed air systems}

In an industrial context, compressed air is viewed as practical and simple to use. In addition, the equipment it powers (e.g. compressed air-driven screwdrivers, blowers or joiners) is typically less expensive than electric tools. However, the efficiency of a CAS is often low for multiple reasons, such as due to a higher system pressure than demanded and leaks in the system (e.g. Björk et al. 2003). From a life cycle cost perspective, the major expense of a CAS is the energy cost of running the system, even if the investment costs of a CAS vary due to the type of compressor and related equipment, for example (e.g. Saidur et al. 2010). Björk et al. (2003) state that the efficiency of compressed air is often lower than $10 \%$. This is acknowledged by Saidur et al. (2010) who show that only $10-20 \%$ of the energy utilised by a CAS is actually related to useful work. Further, a CAS is often integrated with the industrial processes in a company, which might challenge energy efficiency possibilities.

Typically, several options can be proposed to improve energy efficiency in a CAS. An optimised and well-functioning system is often equal to an energy-efficient system. That is, if factors such as air quality, working pressure, regulation, air use, power requirements, energy recovery and maintenance are optimised, the CAS operates both efficiently and energy efficiently. Properly planned maintenance of the CAS will not only increase the lifetime of the compressor and the ancillary equipment, along with their operational reliability, but will also support a wellfunctioning and energy-efficient system. Further, since all the sub-parts of a CAS are connected, these parts affect each other as well as the whole system. Therefore, it is important to take a holistic view of the entire system when analysing and attempting to improve the efficiency and energy efficiency of a CAS.

The energy use of a CAS mainly depends on the working pressure; the higher the required pressure, the more energy needed to compress the air. A CAS is comprised of several sub-parts, i.e. ancillary equipment such as filters, dryers, valves, receivers and piping, and all these parts can create pressure drops. For instance, redundant filtration results in elevated pressure drops, which in turn require a higher pressure at the point of production, thus increasing the energy use of the system. Further, the energy use of a CAS also increases with the quality requirements. Understanding the actual requirements is an important part of operating an efficient system. Therefore, the design of the distribution system must consider a number of factors: low pressure drops between the compressor and the end-use equipment, the minimisation of leaks from the 
piping and optimal condensation if an air dryer is lacking. These and other factors affect the efficiency and reliability and thus the cost of operating a CAS. Documentation and analysis of production routines and processes can help to match the use of compressed air to the demand. A combination of compressors, along with a control and regulation system, provides flexibility in adjusting the use of compressed air to the production demand, and this will contribute to improving the energy efficiency of the CAS. The use of the excess heat from the compressor, i.e. energy recovery, will also improve the energy efficiency of the system.

Neale and Kamp (2009) find that 50-70\% of the energy efficiency potential relates to the demand side (e.g. sealing of leaks and reduction of artificial demand). In addition, the authors find that investment costs and payback periods for the demand-side measures are lower than they are for the supply-side measures. The authors point out that risk might contribute to the figures on the supply side; in general, processing and manufacturing industries often install oversized CASs. Neale and Kamp (2009) further stress the importance of independent auditing to identify opportunities on the demand side of a system.

\section{Factors influencing decisions on industrial energy efficiency measures}

Despite the existence of cost-effective industrial energy efficiency measures, not all are implemented. It is important to study the barriers to and drivers for industrial energy efficiency to understand the reasons why these measures are not always implemented. In this section, some previous studies on barriers and drivers are presented, along with research involving specific energy efficiency measures. At the end of this section, the concept of industrial NEBs is introduced.

\subsection{Barriers to implementation of industrial energy efficiency measures}

Barrier theory is a comprehensive perspective that is commonly applied to explain the gap between optimal and realised levels of energy efficiency by combining economic, behavioural and organisational parameters. For example, Sorrell et al. (2000) apply this perspective to categorise the barriers to energy efficiency as presented in Table 1 below.

Table 1. Classification of barriers to energy efficiency (based on Sorrell et al. 2000).

\begin{tabular}{|l|l|}
\hline Theoretical perspective & Theoretical barrier \\
\hline Economic non-market failure & Heterogeneity \\
\cline { 2 - 2 } & Hidden costs \\
\cline { 2 - 2 } & Access to capital \\
\cline { 2 - 2 } Economic market failure & Risk \\
\cline { 2 - 2 } & Imperfect information \\
\cline { 2 - 2 } & Split incentives \\
\cline { 2 - 2 } & Adverse selection \\
\cline { 2 - 2 } & Principal-agent relationships \\
\cline { 2 - 2 } & Bounded rationality \\
\cline { 2 - 2 } & Form of information \\
\cline { 2 - 2 } & Credibility and trust \\
\cline { 2 - 2 } & Inertia \\
\cline { 2 - 2 } & Values \\
\hline Organisational & Power \\
\cline { 2 - 2 } & Culture \\
\hline
\end{tabular}

Cagno et al. (2013) present another theoretical approach to categorising barriers to industrial energy efficiency and divide barriers in external and internal barriers with respect to an industrial company. Empirical studies of barriers to industrial energy efficiency have been conducted extensively in various contexts and from different perspectives. The studies show that the barriers vary according to regions and industrial sectors (e.g. De Groot 2001; Rohdin et al. 2007; Rohdin 
and Thollander 2006; Sardianou 2008; Sorrell et al. 2004; Thollander and Ottosson 2008; Trianni and Cagno 2012).

Major barriers in small- and medium-sized manufacturing enterprises (SMEs) in Germany are high investment costs and lack of capital (Fleiter et al. 2012). For small- and medium-sized Italian enterprises, Trianni and Cagno (2012) find that the major barriers to energy efficiency perceived by the firms are access to capital, lack of (or imperfect) information on cost-efficient energy efficiency interventions, and the form of information. Studies of firms in the Netherlands by de Groot et al. (2001) show that other investments are more important as a main barrier, which Venmans (2014), who finds that major barriers in the ceramic, cement and lime sector in Belgium are other priorities for capital investments and hidden costs, acknowledges. Harris et al.'s (2000) study of Australian manufacturing sectors identifies firms' perceptions regarding low rates of return and long payback periods as major barriers.

Barriers to industrial energy efficiency are also studied in various sectors in Sweden. Among nonenergy-intensive manufacturing firms, major barriers are, for instance, cost and risk of production disruption, lack of time or other priorities, cost of obtaining information on the energy consumption of purchased equipment, and other priorities for capital investments (Rohdin and Thollander 2006); major barriers found in the foundry sector are technical risk (e.g. production disruptions) and lack of budgetary funding (Rohdin et al. 2007); pulp and paper firms rank cost and risk of production disruption, inappropriate technology at the mill, lack of time or other priorities, lack of access to capital and slim organisation as major barriers (Thollander and Ottosson 2008); and firms belonging to the iron and steel industry state that major barriers are technical risks, limited access to capital and other priorities for financial investments (Brunke et al. 2014).

Previous research on barriers has, with few exceptions (Cagno and Trianni 2014; Fleiter et al. 2012), studied barriers to energy efficiency as a single entity; that is, barriers to the specific energy efficiency measures for various processes or technologies have not been investigated. However, the characteristics of energy efficiency measures affect their adoption and implementation (Cagno and Trianni 2014; Fleiter et al. 2012). In a study based on manufacturing SMEs in Italy, Cagno and Trianni (2014) investigate the barriers to specific energy efficiency improvement measures for lighting, compressed air, motors and HVAC, concluding that different barriers are perceived for specific energy efficiency measures, and they vary depending on the characteristics of the measures. Concerning energy efficiency improvement measures for CASs, Cagno and Trianni (2014) find that the following barriers are highly ranked by the studied Italian SMEs: lack of information on costs and benefits, unclear information from technology providers and uncertain trustworthiness of the information source.

Hanna and Baker (2000) find that there are a number of factors that hinder the adoption and implementation of efficiency improvements in CASs, for instance: lack of cost information (operations, maintenance and financial managers lack information on the cost of operating CASs - they do not recognise it as a source of potential cost savings); lack of understanding a CAS (operations and maintenance managers do not understand how the CAS works as a whole and what affects its efficiency; therefore, companies buy new equipment rather than optimise the existing system); the CAS is viewed as a low-priority system by operations and financial managers and only gets attention when production is threatened; financial managers do not consider life cycle costs when investing in CAS improvements; there is a lack of credible information (costs, benefits, risks and applicability) about strategies for reducing CAS costs; lack of skills to implement and maintain CAS improvements by the plant's operations and maintenance staff; and operations and maintenance staff cannot internally sell CAS improvements due to lack of time, skills or organisational standing to convince financial managers. As Marshall (2012) stresses, an efficient and optimised system often corresponds to an efficient CAS. The barriers above, stated by Hanna and Baker (2000), could therefore be viewed as barriers not only to efficiency improvements, but also to energy efficiency improvement measures for CASs. 
Barriers to energy efficiency can also be related to their impact on the different steps of the decision-making process. Results from Trianni et al. (2016) show that the greatest resistance is found in the first steps of the decision-making process. For instance, lack of awareness and behavioural barriers are crucial in the beginning of the process, but lower in the final steps, which could prevent companies from evaluating or recognising possible energy efficiency measures. Economic barriers are ranked highest; however, their effect is mainly limited to the step of financial analysis, according to Trianni et al. (2016).

\subsection{Drivers for implementation of industrial energy efficiency measures}

The drivers for industrial energy efficiency have not been subject to the same amount of intensive research as the barriers. Even so, the knowledge on drivers plays an important role in the adoption of energy efficiency measures. In most empirical studies, people with real ambitions, long-term energy strategies and the threat of rising energy prices have been shown to be important drivers for energy efficiency (e.g. Apeaning and Thollander 2013; Cagno and Trianni 2013; Hasanbeigi et al. 2010; Rohdin et al. 2007; Thollander and Ottosson 2008). Lee (2015) adds cost savings as an important driver and Trianni et al. (2016) show that economic drivers are perceived as the most important by manufacturing companies in Italy.

Applying their classification scheme to energy efficiency measures, Fleiter et al. (2012) find that it is not the energy efficiency measure itself that hinders its adoption; rather, the characteristics (e.g. payback period, investment cost, relation to core process, and type of measure) of the measure are the problem. Hence, the adoption of energy efficiency measures faces different obstacles depending on the characteristics of the specific measure. The same applies to possible drivers for energy efficiency; measures associated with higher adoption rates probably demonstrate characteristics that act as sufficiently good drivers to motivate their adoption and implementation (Fleiter et al. 2012). Trianni et al. (2014) also stress the importance of the characteristics of energy efficiency measures in relation to their adoption. Developing a framework for characterising energy efficiency measures, the authors conclude that the attributes of the measures with higher adoption rates may act as drivers for energy efficiency.

Apart from studies on the characteristics of energy efficiency measures in relation to their adoption, previous research has not addressed what drives implementation of specific energy efficiency measures for specific industrial energy-using processes, of which compressed air is one. Studying the drivers for energy efficiency from different perspectives and on different levels will deepen the understanding and guide decision-makers and policymakers in implementing and promoting energy efficiency measures (Fleiter et al. 2012; Trianni et al. 2014).

\subsection{Non-energy benefits of industrial energy efficiency measures}

Industrial energy efficiency is often stressed as an important means for reaching climate and energy targets, but energy efficiency might have other positive side effects as well: so-called nonenergy benefits (NEBs). Energy efficiency improvement measures in industry could yield a number of outcomes beyond energy and energy cost savings, for instance, increased productivity, improved product quality, reduced waste and reduced maintenance (e.g. Finman and Laitner 2001; Hall and Roth 2003; Laitner et al. 2001; Lilly and Pearson 1999; Lung et al. 2005; Pye and McKane 2000; Worrell et al. 2003). Most industrial NEBs can be classified into the following categories: production, operation and maintenance, working environment, waste and emissions (Finman and Laitner 2001; Hall and Roth 2003; Laitner et al. 2001; Lilly and Pearson 1999; Lung et al. 2005; Pye and McKane 2000; Worrell et al. 2003).

Pye and McKane (2000) argue that if NEBs are monetised and included in the investment calculations in industrial energy efficiency projects, the financial aspects of such investments will be enhanced. This is acknowledged by Finman and Laitner (2001) who state that if NEBs are considered and assigned monetary value (if possible), it could result in halving the payback time for the projects. Laitner et al. (2001) suggest that the NEBs related to production, operation and maintenance, waste and emissions could be quantified accordingly, but benefits that improve the working environment might be more difficult to quantify and monetise. 
Given the findings above, it seems clear that omitting NEBs from evaluations of investments or energy efficiency improvement measures could result in an underestimation of the financial potential of such investments or measures. Moreover, these findings also stress the importance of monetising the NEBs in order to incorporate them into investment calculations. However, as concluded by Nehler and Rasmussen (2016), while NEBs are not commonly included in investment calculations, communicating the benefits in terms of cost and revenue might be a way to ease the incorporation of the benefits into the calculations. Of course, in order to make energy efficiency investment evaluations and calculations as accurate as possible, the negative impacts should also be considered. Even benefits that cannot be monetised might play an important qualitative role in investment decisions, depending on the role and magnitude of such benefits (Nehler and Rasmussen 2016).

NEBs have been studied and reported in various ways, but, as described above, most studies have focused on the total monetary impact that the benefits have on all energy efficiency projects studied. The specific NEBs of individual energy efficiency projects or measures have often gone unreported. However, Lilly and Pearson (1999), Pye and McKane (2000), Laitner et al. (2001) and Trianni et al. (2014) report on particular NEBs perceived after the implementation of specific energy efficiency measures, and Skumatz and Dickerson (2000) report on the non-energy benefits of a few industrial processes, such as lighting and HVAC.

NEBs vary, and their effects might add extra value in different areas within a company. Hence, a broad perspective must be applied to recognise all the benefits that energy efficiency measures might yield. At the same time, the NEBs of specific energy efficiency measures should be investigated since such knowledge might contribute to overcoming barriers or even drive specific energy efficiency measures.

\section{Method}

This study is based on a combined approach using both interviews and a questionnaire. Interviews with industrial energy managers (i.e. the users), independent energy audit experts for CASs and suppliers of CASs were carried out to gain an understanding of the barriers to and the drivers for energy efficiency measures for CASs. Hence, the research design includes not only the energy managers as respondents providing their experiences of energy efficiency in CASs, but also covers the auditors' (i.e. the field experts') perspectives within their role as information providers. In addition, their perspectives were complemented with the views of the suppliers of CASs. In total, 16 interviews were conducted: five with energy managers; five with energy audit experts on CASs; and six interviews with suppliers of CASs. With regard to the NEBs, a questionnaire was sent out to energy audit experts to capture their views on perceived NEBs related to energy efficiency improvement measures for CASs, followed by interviews with suppliers of CASs. Viewing the problem from more than one perspective provides a deeper understanding, but it also contributes to data triangulation by combining different data sets. In previous studies of barriers, drivers and NEBs, the analysing variable has been the decision to invest in and implement costeffective energy efficiency measures. Accordingly, in this study, the analysing variable is defined as the decision to invest in and implement cost-effective energy efficiency CAS measures. As suggested by Yin (2009), the interview guides and the questionnaire applied were all reviewed by senior research staff prior to its use.

The empirical data collection in this study has been conducted through a process consisting of three phases. In the first phase, data collection began by conducting interviews with industrial energy managers (users) and energy audit experts for CASs, considering their view on barriers to and drivers for energy efficiency in a CAS. In that phase, only energy managers and auditors were included. Thereafter, in the second phase, the study was extended to consider NEBs in relation to CASs, and to that end, auditors were asked about their experiences. In the last phase, the empirical data of this study was further extended by collecting the suppliers' perspectives. Hence, the empirical data collection evolved over the time it was conducted. Therefore, the methods used for 
data collection, topics, respondents and context differ in each phase. In Figure 2, the empirical data collection process is illustrated.

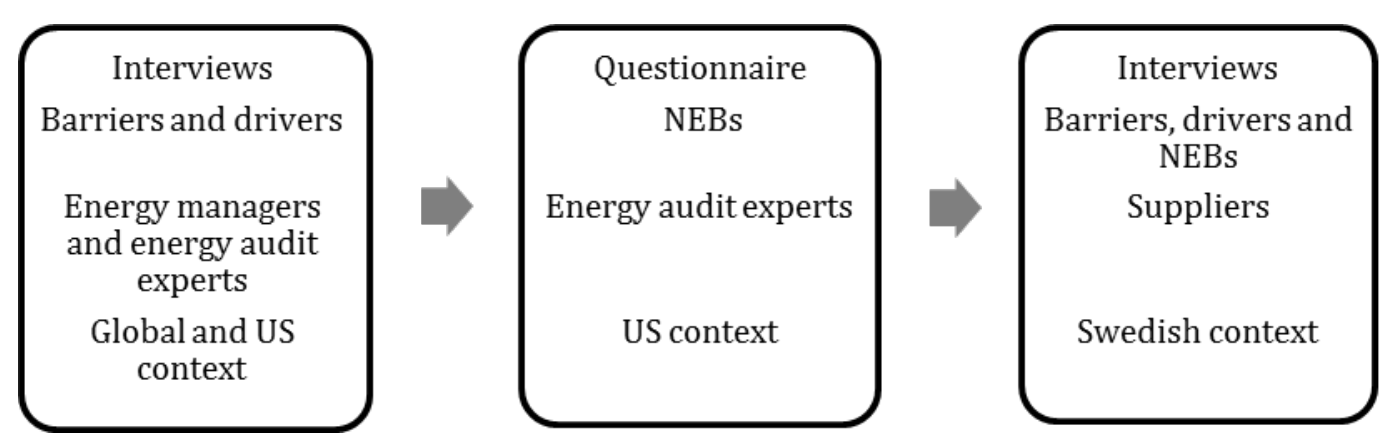

Figure 2. An illustration of the empirical data collection process displaying the types of data collection methods, topics, respondents and contexts.

In the sections below, the data collection process is described in more detail, including characteristics of the samples.

\subsection{Interviews with the energy managers (users), the energy auditors (experts) and the suppliers}

In total, 16 interviews were carried out, five of which were conducted with corporate-level representatives-energy managers-from multinational industrial manufacturing companies. Energy managers contribute with a comprehensive perspective on energy-related issues within the companies, along with more specific knowledge of the companies' energy-using processes, which also makes these respondents suitable for studies examining specific energy-using processes such as CASs. Even though energy efficiency goals are set across the entire organisation, the production manager will focus on production goals, for example, and the maintenance manager will probably focus on keeping the equipment running. Therefore, an energy manager may generally provide a more real picture of energy efficiency improvements within the company and what drives and hinders them, and provide specific examples of their experiences in energy auditing and implementing energy efficiency measures in their CASs. Hence, the main criterion when selecting interviewees was energy managers that was centralised and independent from the operations at the companies. The names of the interviewees and the companies have been anonymised. Table 2 shows the positions of the interviewees, the companies' business types and the numbers of employees.

Table 2. Background information on the interviewees' positions in their companies.

\begin{tabular}{|c|l|l|l|}
\hline Interviewee & Position & Type of business & $\begin{array}{l}\text { Number of } \\
\text { employees }\end{array}$ \\
\hline $\mathbf{1}$ & Global energy manager & Meat casing & $>5000$ \\
\hline $\mathbf{2}$ & $\begin{array}{l}\text { Region project manager, Bellevue, OH, US } \\
\text { (former energy manager) }\end{array}$ & $\begin{array}{l}\text { PET beverage } \\
\text { containers }\end{array}$ & $>37800$ \\
\hline $\mathbf{3}$ & $\begin{array}{l}\text { Region engineering director, US (former } \\
\text { energy manager) }\end{array}$ & Paints and coatings & $>28000$ \\
\hline $\mathbf{4}$ & Global energy manager, Europe & Chemical company & $>40000$ \\
\hline $\mathbf{5}$ & $\begin{array}{l}\text { Region energy and sustainability manager, } \\
\text { US }\end{array}$ & Food packaging & $>11000$ \\
\hline
\end{tabular}

Five other interviews were conducted with independent energy audit experts in CASs from different consultancy firms in the US. The choice to interview energy auditors specialised in CASs and not energy auditors in general was due to their focus on the entire CAS, i.e. both the supply side and the demand side, and due to their experience in analysing and proposing energy 
efficiency improvement measures specifically targeted for CASs. Table 3 presents the positions of the audit interviewees, the firms and their aggregated experience (displayed as the number of energy audits conducted).

Table 3. Background information on the CAS energy auditor experts.

\begin{tabular}{|c|l|l|l|l|}
\hline Interviewee & Position & Name of the firm & $\begin{array}{l}\text { Affiliated with } \\
\text { equipment suppliers }\end{array}$ & $\begin{array}{l}\text { Records } \\
\text { of audits }\end{array}$ \\
\hline $\mathbf{1}$ & $\begin{array}{l}\text { System } \\
\text { auditor/owner }\end{array}$ & Crowsnest Ltda. & No & $<50$ \\
\hline $\mathbf{2}$ & System auditor & IZ Systems LLC & No & $<100$ \\
\hline $\mathbf{3}$ & $\begin{array}{l}\text { System auditor/ } \\
\text { general manager }\end{array}$ & IZ Systems LLC & No & $>300$ \\
\hline $\mathbf{4}$ & System auditor & $\begin{array}{l}\text { Southern Corporation } \\
\text { of SC }\end{array}$ & No & $>300$ \\
\hline $\mathbf{5}$ & $\begin{array}{l}\text { System } \\
\text { auditor/owner }\end{array}$ & $\begin{array}{l}\text { Compressed Air } \\
\text { Consultants }\end{array}$ & No & $>200$ \\
\hline
\end{tabular}

The data collection for the interviews with the users and energy audit experts was based on an interview guide that began with open-ended questions and concluded with a more structured part (inspired by, e.g. Kvale and Brinkmann 2009). Hence, in the first part the respondents could speak freely about aspects of energy efficiency related to CASs across the corporation and how information was retrieved on energy efficiency improvement measures for CASs. In the structured part of the guide, the respondents were asked to rank the drivers' and barriers' impacts on the implementation of cost-effective energy efficiency improvement measures for CASs. The selection of barriers and drivers included in the structured part was influenced by previous research by Rohdin and Thollander (2006) and Brunke et al. (2014). The barriers and drivers tested are summarised in Appendix A.

Six interviews were conducted with salespeople at CAS supply companies. The rationale for including this group of respondents was to add the suppliers' perspectives, particularly on perceived NEBs. Table 4 presents information on the interviewees.

Table 4. Background information on the CAS salespeople.

\begin{tabular}{|c|l|l|}
\hline Interviewee & Position & Supply company \\
\hline $\mathbf{1}$ & Sales project engineer & $\mathrm{A}$ \\
\hline $\mathbf{2}$ & Sales engineer & $\mathrm{A}$ \\
\hline $\mathbf{3}$ & Sales engineer & $\mathrm{B}$ \\
\hline $\mathbf{4}$ & Sales engineer & $\mathrm{B}$ \\
\hline $\mathbf{5}$ & Business developer & $\mathrm{C}$ \\
\hline $\mathbf{6}$ & Energy efficiency project engineer & $\mathrm{D}$ \\
\hline
\end{tabular}

The interviews were based on an interview guide, and with the exception of the general information questions, the guide focused on perceived NEBs related to energy efficiency measures for CASs. First, NEBs were addressed by asking an open question, and then possible NEBs for specific energy efficiency measures for CASs were explored. The measures were chosen according to a taxonomy of energy efficiency measures (Blomqvist and Thollander 2014; Söderström et al. 1994): conversion to electric-driven tools, sealing of leaks, heat recovery, systems management (e.g. variable speed drive [VSD]), and lower system pressure. However, three additional measures-maintenance of ancillary equipment, air inlet measures and measures related to enduse equipment-were added in order to cover the entire CAS. The interviewees were not approached with a list of proposed NEBs. Instead, they were asked to report on possible NEBs based on their role as a salesperson, as well as on possible NEBs in relation to the given energy efficiency measures for CASs. Moreover, questions were asked about how the NEBs were used, for instance, as sales arguments or in offers to customers, and if NEBS were quantified and monetised. Finally, questions were asked about why customers reach, or do not reach, positive decisions on 
investments and measures in energy efficiency improvements for CASs, i.e. factors driving or hindering energy efficiency measures for CASs.

\subsection{Questionnaire to energy auditors (experts) for CASs}

Conducting interviews with the users and experts, raised an interest in studying possible NEBs. The group of energy audit experts was chosen as respondents and this decision was based on their aggregated experience in auditing and implementing energy efficiency projects in CASs of all sizes and characteristics, as well as their experience in evaluating such projects. The data collection regarding the NEB part of this study was conducted via a questionnaire that was distributed to the independent energy audit experts (see Table 3, above). The NEBs considered in the questionnaire were those commonly tied to industry in the previous NEB literature (e.g. Finman and Laitner 2001; Hall and Roth 2003; Laitner et al. 2001; Lilly and Pearson 1999; Lung et al. 2005; Pye and McKane 2000; Worrell et al. 2003). Table 5 lists the NEBs tested in the questionnaire. Since these were selected and tested in a previous study (Nehler and Rasmussen 2016), the same NEBs were used in this study, along with the addition of the NEB capital avoidance. A compilation of the NEBs tested are displayed in Appendix A.

The respondents were first asked about perceived NEBs after the implementation of energy efficiency projects using a five-point Likert scale: strongly disagree $=1$, disagree $=2$, neutral $=3$, agree $=4$, strongly agree $=5$, indifferent $=0$; According to your aggregated experience of auditing plants and implementing energy savings projects in compressed air systems of all sizes and characteristics, to what extent do you agree or disagree with the following as perceived NEBs as a result of the implementation of energy savings retrofit projects? In addition, there was an opportunity to mention other benefits not included in the questionnaire. To address the role of NEBs as drivers, a question was asked regarding their potential contribution to the decisionmaking processes of energy efficiency projects using the five-point Likert scale provided above: To what extent do you agree or disagree that NEBs complement energy savings in the decisionmaking process? Moreover, this question was also based on the NEBs given in Appendix A.

\section{Results and discussion}

\subsection{Barriers}

The results displayed in Figure 3 below show barriers to energy efficiency in CASs as perceived by the users (energy managers) and the experts (energy auditors). The main barriers are related to the investment, i.e. financial and economic issues, such as access to capital and costs related to the implementation of energy efficiency measures. For instance, as stated by the respondents, the primary issue is other priorities for capital investments, and the second is access to capital, followed by lack of budget funding, energy objectives not integrated into operating maintenance or purchasing procedures, cost of identifying opportunities, analysing cost effectiveness and tendering, cost of production disruption/hassle/inconvenience, of which all, except energy objectives not integrated into operating maintenance or purchasing procedures, could be considered economic-related barriers. Further, based on Sorrell et al.'s (2000) theoretical classification, these main barriers can be sorted as economic non-market failures, whereas the barrier energy objectives not integrated into operating maintenance or purchasing procedures is of organisational character. Economic and financial issues have been shown to be main barriers in previous studies (e.g. Fleiter et al. 2012; Venmans 2014; Harris et al. 2000; Thollander and Ottosson 2008; Brunke et al. 2014). The role of economic issues as barriers has also been shown to be related to the decision-making process on energy efficiency investments; however, mainly as barriers to the step of financial analysis (Trianni et al. 2016). The results of this study also indicate that some of the other barriers ranked highly by the respondents were of an organisational nature; for instance, energy objectives are not integrated in operating maintenance and purchasing procedures, department/workers are not accountable for energy costs, slim organisation, lack of time and other priorities, and long decision chains. Organisational factors 
have previously been stated as barriers to energy efficiency in larger companies with high energy use related to their production (e.g. Lee 2015; Rohdin et al. 2007; Thollander and Ottosson 2008).

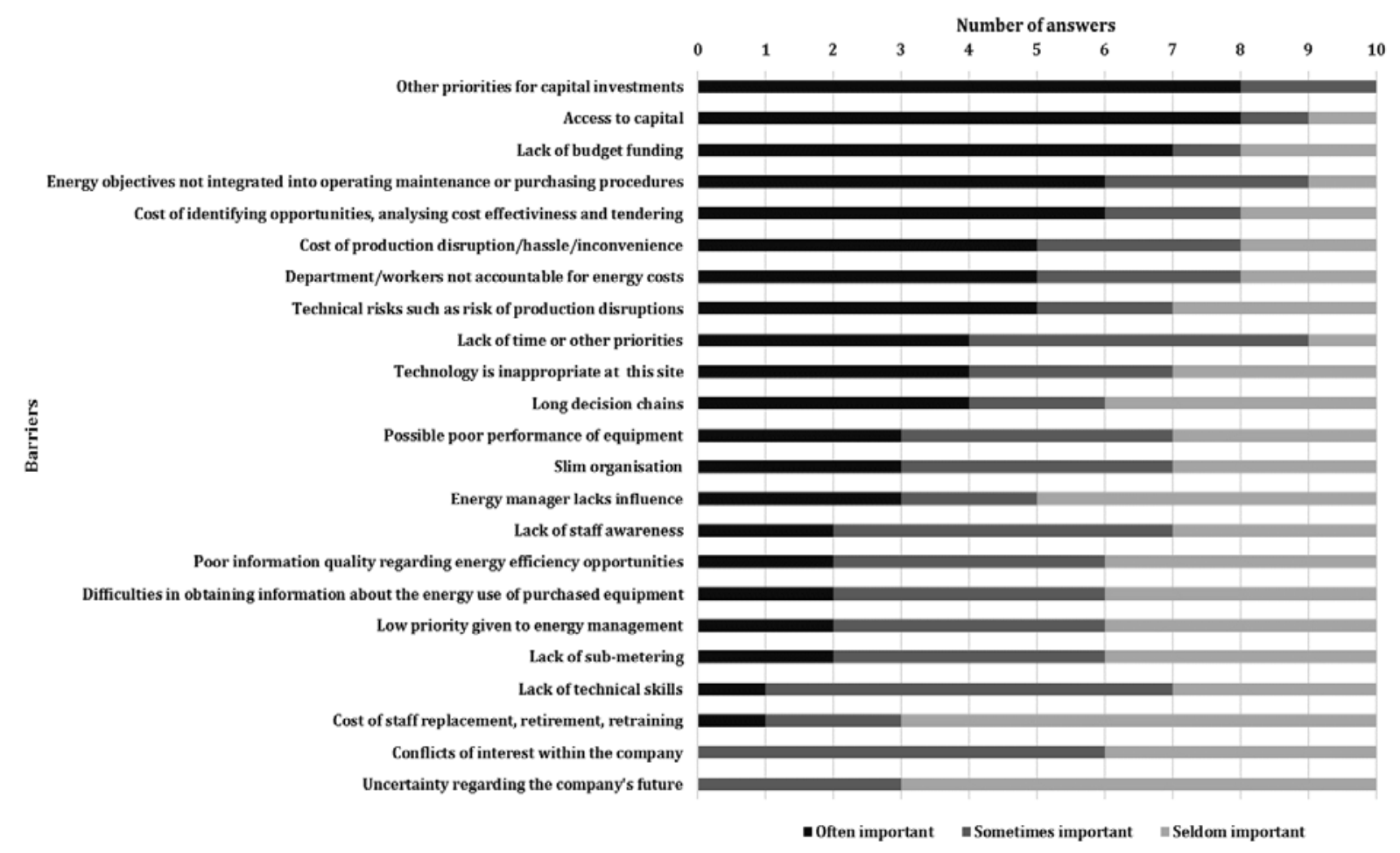

Figure 3: Importance of barriers to the implementation of cost-effective energy efficiency measures in CASs as perceived by users and experts.

Apart from the high ranking of, for instance, access to capital and other priorities for capital investments, the view of suppliers revealed that other common reasons for customers to not invest in energy efficiency measures for CASs include specific organisational aspects. Energy efficiency measures not being the core business; lack of support by top management for energy efficiency projects for CASs; other energy efficiency projects being chosen instead of CAS projects; and lack of foresight on the part of the decision makers in the company were stated as barriers to energy efficiency CAS measures by the suppliers. One of the suppliers also stated that customers are sometimes sceptical of the trustworthiness of the information presented by the suppliers regarding the potential of the CAS measures. Hence, in relation to the theoretical framework by Sorrell et al. (2000), the view of the suppliers reveals that main barriers to CASs energy efficiency measures are related to economic non-market failures and organisational barriers.

The results presented above differ from those of Cagno and Trianni (2014), who find that the main barriers in CASs are related to information (e.g. lack of information, or unclear information). However, it should be pointed out that the study presented in this paper is based on a limited sample; further, as stressed by Cagno et al. (2013), firm size seems to have an impact on barriers to the implementation of energy efficiency measures. The study of Cagno and Trianni (2014) is based on SMEs, whereas the views of the users and audit experts in this study relate to large companies.

\subsection{Drivers}

The responses gathered from the interviews with users (energy managers) and experts (energy auditors) indicate an emphasis on organisational and economic aspects as drivers for energy efficiency measures in CASs. Figure 4 shows the combined results concerning the drivers for energy efficiency in CASs as perceived by the two groups. 




Figure 4: Importance of drivers for the implementation of cost-effective energy efficiency measures in CASs as perceived by users and experts.

The two main drivers according to the respondents are of organisational character; commitment from top management and people with real ambition, followed by a driver of economic nature, cost reductions from lowered energy use. All respondents also agreed on that long-term energy strategy, energy management system (EMS) and threat of rising energy prices were important drivers to energy efficiency measures in compressed air systems. The majority of the respondents agreed that compressed air is an excellent target for energy efficiency because it is easy to identify the related savings and the paybacks are often attractive. This might have contributed to that cost reductions from lowered energy use was perceived as an important driver by the respondents.

Even though commitment from top management was perceived as the most important driver for energy efficiency measures in CASs, some of the respondents (users) stressed in the interviews that they receive considerable pressure from top management to reduce costs. Furthermore, energy management systems seems to play an important role. Having any sort of sub-metering helps energy managers accurately show the extent of costs involved in CASs, and this is advantageous for raising capital for energy efficiency projects. Often, energy managers need to fight against the perception that compressed air is free when there is a lack of sub-metering. In such cases, an energy manager (or a person with a similar role) with real ambition becomes very critical because that person is probably the one that has to push energy efficiency issues forward.

The suppliers listed organisational aspects, such as people with real ambitions and having a longterm perspective on energy efficiency measures for CASs, together with economic aspects, such as the high profitability of energy efficiency CAS measures (generally short payback periods) and the inclusion of energy efficiency investments in the budget. Another important driver mentioned by the suppliers was knowledge regarding the impacts of energy efficiency measures for CASs, i.e. understanding the potential of the measures and potential environmental concerns. 
The main drivers for energy efficiency CASs measures as perceived by the users and experts (for instance, people with real ambitions, long-term energy strategy and the threat of rising energy prices) have also been listed in previous literature as important drivers to energy efficiency in general (e.g. Apeaning and Thollander 2013; Cagno and Trianni 2013; Hasanbeigi et al. 2010; Rohdin et al. 2007; Thollander et al. 2013; Thollander and Ottosson 2008; Lee 2015). Trianni et al.'s (2016) study also shows that the economic drivers are perceived as important, and according to their results, economic drivers seem to play an important role for CASs' measures as well. Moreover, many of the drivers in this study which were stated as important by the respondents, seem to be related to companies' organisational aspects.

The views of the users, experts and suppliers paint a consistent picture: organisational and economic drivers are important factors in making positive decisions on energy efficiency investments and measures in CASs.

\subsection{NEBs}

\subsubsection{NEBs after implementation as perceived by the experts}

The results from the questionnaire to the experts are displayed in Figure 5, and as can be seen, from the perspective of the experts, all of them agreed on to have observed more reliable production as a benefit of energy efficiency CASs measures. Several energy efficiency measures for CASs are directed towards an efficient system, and as a consequence, the production of air might be more stable. However, other production-related factors have also be observed; for instance, improved air quality, improved product quality and the production might increase. This may explain why production-related benefits were perceived by most of the experts.

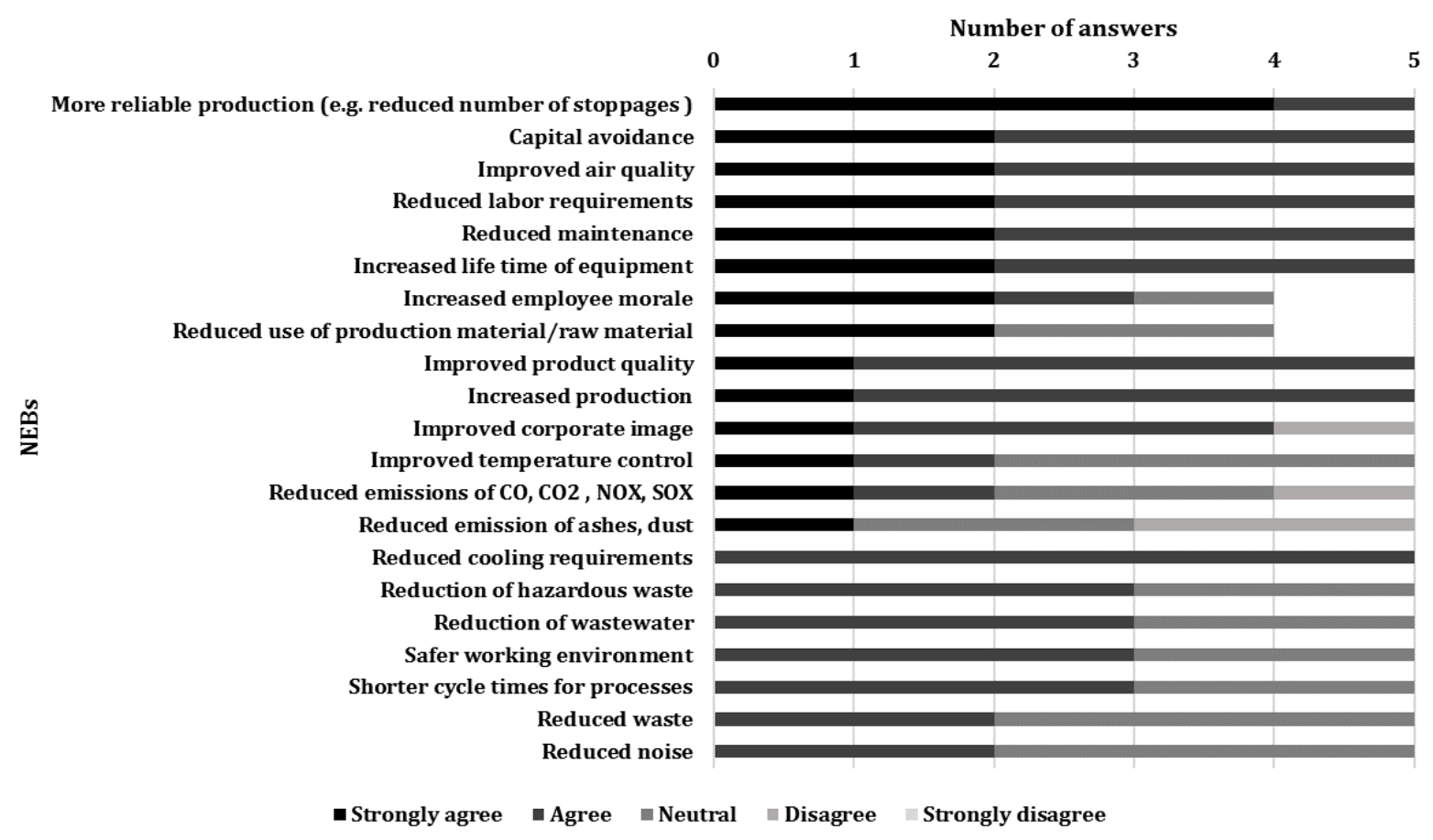

Figure 5: NEBs after implementation of energy efficiency measures in CASs as perceived by the experts.

Capital avoidance was ranked as the second highest NEB by the respondents. The use of compressed air in companies' production processes can be analysed by documenting the routines and processes to match the use to the load on the compressor(s), i.e. the focus shifted to the demand side. Hence, optimisation of the CAS, combined with energy efficiency improvement measures, can be a way to handle the workload on the compressors rather than investing in new ones. This might explain why capital avoidance was ranked as a very high NEB. In addition, the interviewees agreed that in many cases rental costs are also part of the NEBs after implementing 
a retrofit project. Companies often obtain rentals to support production during a machine breakdown, and due to concerns related to production, they remain running.

The benefits of reduced labour requirements, reduced maintenance and increased lifetime of equipment are in one way or another related to the operation and maintenance of the equipment. Compressed air can contain water, oil and different types of particulates, so to achieve the required air quality, the air passes through various types of filters and dryers. To a lesser or greater extent, all filters lead to a pressure drop in a CAS, which often results in higher energy use. Hence, energy efficiency improvement measures related to different air treatments will not only lead to improved energy efficiency, but also support a well-functioning CAS. This might have contributed to the high rankings for reduced labour requirements, reduced maintenance and increased lifetime of equipment. Indirectly, this might also have an impact on production-a wellfunctioning CAS supports stable production, which might be a factor in why more reliable production was the highest ranked barrier. Clearly, energy efficiency improvements, subject to various air treatments, will affect energy use and air quality, which could explain why improved air quality was the third highest ranked NEB.

\subsubsection{NEBs as drivers to implementation as perceived by the experts}

The experts were also asked about their views on the impact of NEBs on the decision to implement energy efficiency projects; that is, to what degree do NEBs complement energy savings in the decision-making process? In Figure 6, ranked NEBs as drivers for energy savings projects are displayed.

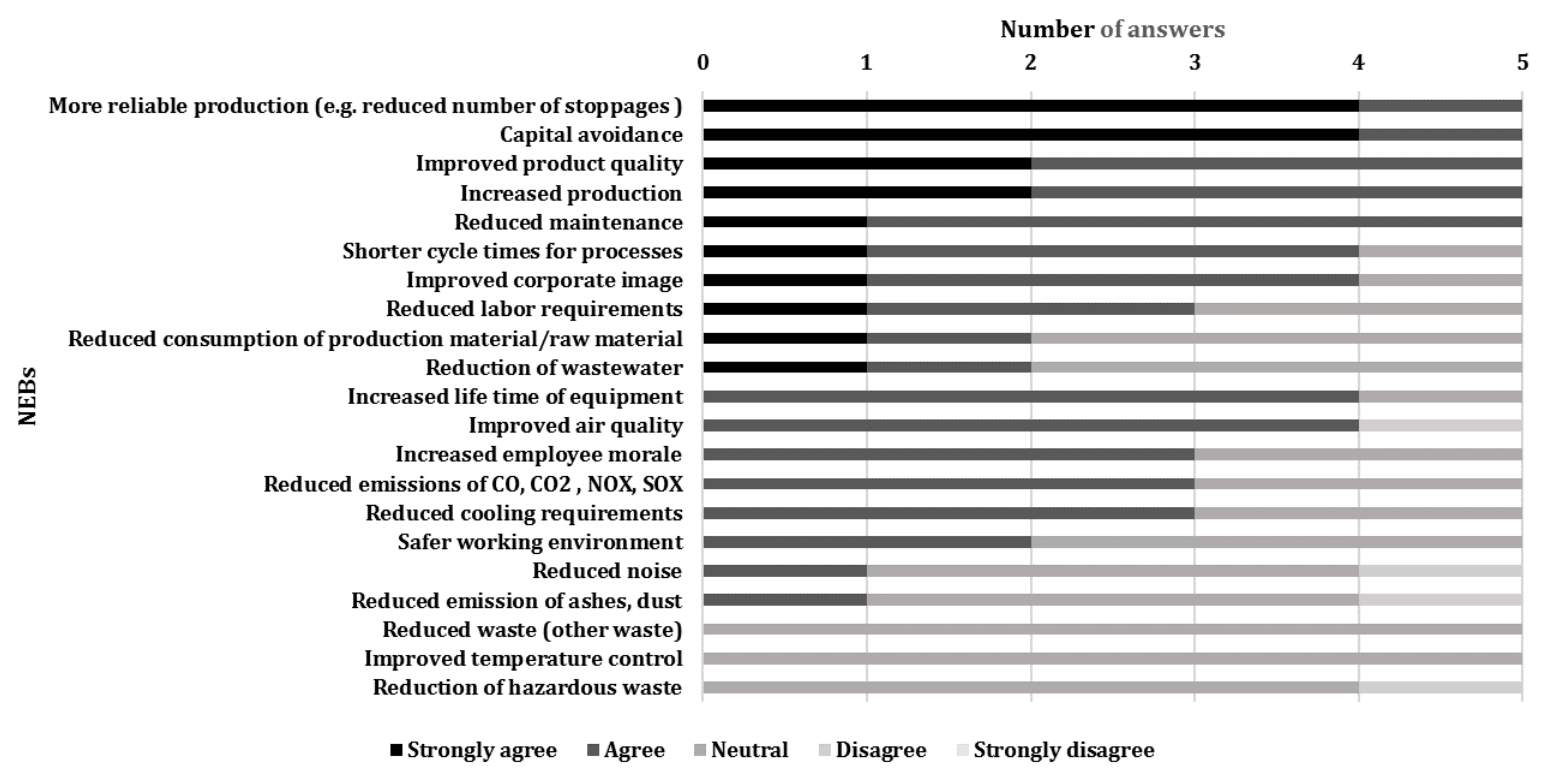

Figure 6: NEBs as drivers to the implementation of energy efficiency CAS projects as perceived by the experts.

All the respondents agreed that the five highest ranked NEBs (more reliable production, capital avoidance, improved product quality, increased production and reduced maintenance) could impact the decision-making processes in energy savings projects, i.e. the stated NEBs could act as drivers for energy efficiency improvement projects. At the same time, these five NEBs were also ranked as major NEBs after the implementation of energy efficiency CAS projects. Three of the highest ranked NEBs (more reliable production, improved product quality and increased production) are directly related to a company's production, i.e. the core business. The absence of a link between energy efficiency and the core business has been stressed as a reason for the nonimplementation of energy efficiency improvement investments (Cooremans 2012). Hence, stressing the fact that energy efficiency improvement measures not only lower energy use but 
also positively affect a company's production might facilitate the implementation of energy efficiency measures for CASs.

The experts further agreed on that capital avoidance and reduced maintenance (ranked as numbers two and five, respectively) were major drivers of energy efficiency improvement measures for CASs. Both of these benefits relate to financial aspects (i.e. reduced costs or reduced expenditures) that are of great importance to companies in their ongoing quest to remain competitive. This connects to what has been addressed previously in the literature (e.g. Finman and Laitner 2001; Pye and McKane 2000): the inclusion of quantified and monetised NEBs will enhance investment proposals for energy efficiency investments. Indeed, avoided or delayed expenditures and reduced costs are compelling to managerial boards, which might support positive decisions regarding the implementation of energy efficiency measures for CASs. However, both capital avoidance and reduced maintenance are effects that might become apparent over a longer timeframe, as compared to the production-related NEBs discussed above. This probably applies to some of the benefits that were ranked lower; for instance, improved corporate image and increased employee morale.

In any event, the benefits as drivers might help to overcome the barriers to energy efficiency improvement measures in CASs. As presented and discussed above, several of the main barriers were related to the investment; for instance, other priorities for capital investments and access to capital. Stressing and acknowledging NEBs like capital avoidance and reduced maintenance might help to overcome investment-related barriers, such as other priorities for capital investments and access to capital, and thereby increase the adoption and implementation of energy efficiency improvement measures for CASs. The same applies to the barriers that were related to the production and equipment, for example, cost of production disruption/hassle/inconvenience, possible poor performance of equipment and technical risks, such as the risk of production disruptions. Presenting information on the production-related benefits, e.g. more reliable production and improved product quality, as possible outcomes of energy efficiency improvement measures for CASs to the departments that are in charge of production and related investments and measures might assist in overcoming these obstacles.

\subsubsection{Specific NEBs as perceived by the suppliers}

Possible perceived NEBs according to the suppliers of CASs were first addressed by an open question related to energy efficiency measures for CASs in general. Then, possible NEBs related to specific energy efficiency measures for CASs were explored. The suppliers stated that energy efficiency measures in general yielded several NEBs after implementation. For instance, noise reduction, improved temperature control, improved operation of the CAS, improved air quality, safer work environment, increased lifespan of equipment (and as a consequence, investments in new equipment are delayed), increased and efficient production, improved product quality, less wear and tear, and more reliable production. These results align with previously reported NEBs in the literature (e.g. Finman and Laitner 2001; Hall and Roth 2003; Laitner et al. 2001; Lilly and Pearson 1999; Lung et al. 2005; Nehler and Rasmussen 2016; Pye and McKane 2000; Worrell et al. 2003), and the results also demonstrate similarities with important NEBs ranked by the experts in this study.

Thereafter, the specific NEBs were explored in relation to eight specific energy efficiency measures for CASs, and the results are displayed in Table 5.

Table 5. NEBs of specific energy efficiency CASs measures as perceived by the suppliers.

\begin{tabular}{|l|l|}
\hline Measure & NEBs \\
\hline $\begin{array}{l}\text { Convert to electric-driven } \\
\text { tools }\end{array}$ & $\begin{array}{l}\text { Improved positioning and power management } \\
\text { Improved control of acceleration/retardation }\end{array}$ \\
\hline Sealing of leaks & $\begin{array}{l}\text { Decreased demand on the compressor } \\
\text { Less compressor back-up capacity }\end{array}$ \\
& $\begin{array}{l}\text { No need to invest in a new compressor due to demand, or the } \\
\text { increased required demand supply is managed by sealing of leaks } \\
\end{array}$ \\
& Less noise, i.e. improved work environment \\
\hline
\end{tabular}




\begin{tabular}{|l|l|}
\hline & $\begin{array}{l}\text { Stable pressure which leads to improved quality of } \\
\text { products/production }\end{array}$ \\
\hline Heat recovery & $\begin{array}{l}\text { Fewer cooling requirements } \\
\text { Lower temperature, i.e. improved work environment }\end{array}$ \\
\hline $\begin{array}{l}\text { System management (e.g. } \\
\text { VSD) }\end{array}$ & $\begin{array}{l}\text { Less fluctuations in air production } \\
\text { Stable pressure } \\
\text { Improved efficiency in the production of compressed air } \\
\text { Increased stability of the system, i.e. a balanced system }\end{array}$ \\
\hline $\begin{array}{l}\text { Reduced system pressure (e.g. } \\
\text { avoidance of oversized system } \\
\text { pressure) }\end{array}$ & $\begin{array}{l}\text { Investments in smaller capacity, or no need to invest in a new } \\
\text { compressor due to demand } \\
\text { Fewer unplanned disruptions or stops in the production } \\
\text { Less wear and tear on the compressor and other equipment } \\
\text { Stable pressure which leads to improved quality in } \\
\text { products/production }\end{array}$ \\
\hline $\begin{array}{l}\text { Maintenance of ancillary } \\
\text { equipment (filters, dryers, } \\
\text { etc.) }\end{array}$ & $\begin{array}{l}\text { Improved air quality } \\
\text { Fewer disturbances in the operation } \\
\text { Reliable operation/production and fewer unplanned production } \\
\text { stops/disturbances }\end{array}$ \\
\hline $\begin{array}{l}\text { Air inlet (lower temperature, } \\
\text { better air quality) }\end{array}$ & $\begin{array}{l}\text { The right quality and temperature of the air creates less wear and tear } \\
\text { on system equipment }\end{array}$ \\
\hline End-use equipment & $\begin{array}{l}\text { Less noise, i.e. improved work environment } \\
\text { Safer work environment } \\
\text { Increased lifespan of the compressor, i.e. investment in a new } \\
\text { compressor will be delayed* }\end{array}$ \\
\hline
\end{tabular}

* For instance, energy-efficient end-use equipment lowers the demand on the compressor, which increases its lifespan.

Most of the energy efficiency measures given in Table 5 are directed towards various parts of the CAS, from the air inlet to the end-use equipment, but a few affect more or less the entire CAS-for instance, sealing leaks and lowering the system pressure. Regardless, it is apparent that various NEBs are perceived in various parts of the system; for instance, energy efficiency measures directed towards the end-use equipment can lead to benefits close to the end-use, such as a safer work environment and less noise, but also to benefits in other parts of the system, like increased compressor lifespan, which is part of the supply side from the beginning of the system. Furthermore, it should be noted that some of the NEBs might also be regarded as energy benefits in a direct way. For instance, sealing of leaks decreases the demand on the compressor which lowers the energy use. However, this measure also indirectly leads to NEBs such as less wear and tear on the compressor which might delay an investment in a new compressor.

The results in Table 5 also show that one type of energy-efficient measure can lead to different types of NEBs. Sealing of leaks, for instance, might yield benefits related to investments (an investment in a new compressor can be delayed or cancelled), production or the work environment. Since these benefits arise in several parts of the CAS and in the company, the benefits are probably perceived by different actors therein. This is the view of the suppliers. However, it indicates that even when studying the NEBs of specific energy efficiency CAS measures at a detailed level, a comprehensive view must be applied to observe all benefits, since CASs often are large, complex systems consisting of several related sub-parts.

\subsection{Combining the perspectives}

Companies experience many different barriers and drivers in relation to energy efficiency measures, and this creates complexity. Therefore, as Meath et al. (2016) note, the role of barriers and drivers in the decision-making process must be taken into account. Moreover, to get a more complete picture, the possible NEBs of energy efficiency measures should be acknowledged, along with their role as possible drivers. In order to tackle the barriers to energy efficiency, it is interesting to investigate what affects energy efficiency measures for various energy-using processes (of which CASs represent one such process). This paper has explored the barriers, drivers and NEBs involved in decisions on energy efficiency measures for CASs from the perspectives of some of the various actors involved: energy managers in their role as users, energy 
auditors in their role as experts and the suppliers of CASs. This paper contributes to the literature by presenting their views of what hinders and drives the implementation of energy efficiency improvement measures for CASs, and which are the additional effects (i.e. the NEBs) that can be gained when investing in energy efficiency measures for CASs.

Empirical barriers that were investigated in previous studies have in this study been tested among users, experts and suppliers of CASs. The results of this study show that highly ranked barriers to energy efficiency in previous studies also seem to be highly ranked barriers to energy efficiency CAS measures. Economic barriers were ranked highly by the users and the experts, while the suppliers also stressed the importance of organisational barriers. Previous studies on specific CAS barriers recognised that informational barriers were most important (Cagno and Trianni 2014), which indicates a discrepancy. However, as described in Section 3.1, factors like the type and sizes of companies and where, in which country or region companies are acting, have been shown to impact on how barriers are perceived (e.g. Cagno et al. 2013), and this might have contributed to the differences. Regardless, it could be an indication that perceived barriers vary-even the barriers to energy efficiency improvements for a specific energy-using process.

Since several of the major barriers found in this study are related to the investments in energy efficiency measures for CASs, an increased focus on behavioural and operational measures on the demand side might be a way to circumvent the barriers, because, as found by Neale and Kamp (2009), these measures tend to have lower investment costs as well as shorter payback periods. This further relates to organisational aspects and establishing routines for energy efficiency in industrial equipment, which was stated as a major driver for energy efficiency improvement measures in CASs. However, even if energy-efficient projects applied to CASs pass the cost-benefit test due to their considerable supply-side potential, efforts should be made to address the demand side as well. Savings on both the supply and demand sides represent a significant opportunity for companies to achieve energy savings under attractive conditions.

Users, experts and suppliers agreed on the main drivers; organisational and economic factors seemed to be important for making positive decisions on energy efficiency investments and measures in CASs. Users of CASs, such as energy managers, need to operate in a supportive environment in which they not only have the capital to fund retrofitting projects, but are also able to obtain complete information. This does not always guarantee that opportunities exist, but at least it offers an impartial analysis. Hence, addressing the importance of organisational aspects, such as well-functioning in-house energy management practices (e.g. Johansson et al., 2011), might be one way to create the foundation and subsequent build-up of a company's energy efficiency routines within CASs. The energy efficiency potential in relation to energy management procedures has previously been stressed by Paramonova et al. (2015). Furthermore, the role of the experts and suppliers as information providers would add to this puzzle.

Experts ranked capital avoidance, more reliable production and improved air quality as important NEBs. Two of these NEBs - capital avoidance and more reliable production-were also ranked as important drivers by the experts. Acknowledging NEBs in decisions and practices in companies might be a way to circumvent what hinders the implementation of energy efficiency measures. Trianni et al. (2017) have described the drivers' and the barriers' effects on the decision-making process, and the roles of NEBs as drivers have previously been stressed by Cagno et al. (2015); among other drivers, NEBs seem to have an impact on almost all barriers. However, this requires that NEBs are acknowledged as drivers. To understand how barriers, drivers and NEBs affect decisions on energy efficiency measures and how these factors affect each other, it is important to involve the different types of actors and persons operating within and outside the company (suppliers), because different actors probably perceive and recognise different NEBs depending on their role and where in the company these people are located. How benefits, barriers and drivers are perceived might therefore vary between different users, actors and groups, which could give them different rankings, but probably also impact how NEBs and drivers are acknowledged and the degree to which barriers will hinder the implementation of energy efficiency measures in CASs. The focus on specific barriers, drivers and NEBs might be one way to 
get a more precise picture, i.e. gaining a deeper understanding of specific drivers and NEBs could be a way to overcome the barriers to the implementation of specific energy efficiency measures.

Furthermore, CASs are complex systems consisting of sub-systems and related parts that are interdependent and linked to one another. Therefore, energy efficiency improvements impact on more than one part of a CAS, and NEBs, as outcomes of the improvements, are thus interrelated and affect one another.

It is important to mention that findings in this study are based on a limited sample, which prevents making generalisations. Even so, the answers from the energy audit experts are based on knowledge gained from conducting several energy audits for CASs in large global companies, while the answers from the energy managers are based on their experiences handling energy issues in large global companies, where CASs are an important support process for industrial applications. Furthermore, the suppliers' salespeople gathered their experience by being involved in several companies' investments in CASs and related equipment. This study have been conducted in various contexts, which might have impacted on the results. In spite of the limitations of the present research, the results presented could guide the direction of future research. Therefore, this study's conclusions are indeed explorative in a field where further research in needed.

Barriers to, drivers for and NEBs of energy efficiency CASs measures have been studied in this paper through various perspectives, the users', the experts' and suppliers' to gain a deeper understanding. However, different perspectives will probably also result in different views on barriers, drivers and NEBs and this have to be addressed in relation to this study as it limits generalisations.

\section{Concluding remarks}

Improved industrial energy efficiency presents challenges of various types since several factors and actors are involved in making decisions on energy efficiency improvements. This paper has explored which factors might affect decisions on energy efficiency measures for CASs by studying the views of some of the different actors, users, experts and suppliers that are involved in actions aiming at improving energy efficiency in CASs. Many previous studies have focused mainly on barriers to, drivers for and NEBs of energy efficiency measures in general. This paper has investigated these factors for one energy-using process: the use of compressed air.

Results of this study indicated that major barriers to energy efficiency in previous studies also seemed to be highly ranked barriers to energy efficiency measures in CASs. Economic barriers were ranked highly by the users and the experts, while the suppliers stressed the importance of organisational barriers. Since the major barriers found in this study were related to the investments in energy efficiency measures for CASs, an increased focus on behavioural and operational measures on the demand side might be a way to circumvent the barriers because these measures tend to have lower investment costs as well as shorter payback periods.

The respondents in this study, users, experts and suppliers, agreed on the main drivers; organisational and economic factors such as commitment from top management, people with real ambition and cost reductions from lowered energy use, which also have been shown to be important drivers to energy efficiency measures in general, seemed to be important for making positive decisions on energy efficiency investments and measures in CASs.

Experts ranked capital avoidance, more reliable production and improved air quality as important NEBs, and capital avoidance and more reliable production were among other NEBs that were also ranked as important drivers by the experts. The interviews with the suppliers revealed that energy efficiency measures for CASs in general yielded several NEBs after implementation. Furthermore, results showed that the NEBs of one specific energy efficiency measure implemented in the CAS could give rise to benefits in various other parts of the system, as well as in the company, and that the benefits were of various types. CASs are complex systems comprising 
interrelated sub-parts. To recognise all the benefits, a comprehensive view is required, even when studying the NEBs of specific measures.

This study contributes to this widened view by investigating energy efficiency CAS measures from some of the involved actors' perspectives. Barriers to, drivers for and related NEBs for energy efficiency improvement measures for CASs in general have been investigated, but also the NEBs related to specific energy efficiency measures for CASs. Awareness of CAS-related NEBs and their role as drivers could be a means to overcome the barriers to energy efficiency improvement measures for CASs and thereby positively impact the adoption rate of such measures. However, this requires further understanding of what hinders and drives specific energy efficiency measures. This study represents an initial explorative attempt to investigate these issues, but future studies in this area are recommended. Future research should also emphasise these aspects for other support processes, such as ventilation and lighting, as well as for their related specific energy efficiency improvement measures. 


\section{References}

Apeaning, R. W., \& Thollander, P. (2013). Barriers to and driving forces for industrial energy efficiency improvements in African industries - A case study of Ghana's largest industrial area. Journal of Cleaner Production, 53, 204-213.

ASME. (2009). EA-4-2009. Assessment for compressed air systems. New York: The American Society of Mechanical Engineers.

Atlas Copco. (2015). Compressed air manual (8th ed.). Belgium: Atlas Copco Airpower NV.

Björk, C., Gralén, K., Räftegård, O., \& Åberg, B. (2003). Den tryckluftslösa fabriken. Eskilstuna, Sverige: Statens energimyndighet.

Blomqvist, E., \& Thollander, P. (2015). An integrated dataset of energy efficiency measures. Energy Efficiency, 8(6), 1125-1147.

Brunke, J-C., Johansson, M., \& Thollander, P. (2014). Empirical investigation of barriers and drivers to the adoption of energy conservation measures, energy management practices and energy services in the Swedish iron and steel industry. Journal of Cleaner Production, 84, 509-525.

Cagno, E., \& Trianni, A. (2013). Exploring drivers for energy efficiency within small- and mediumsized enterprises: First evidences from Italian manufacturing enterprises. Applied Energy, 104, 276-285.

Cagno, E., \& Trianni, A. (2014). Evaluating the barriers to specific industrial energy efficiency measures: An exploratory study in small and medium-sized enterprises. Journal of Cleaner Production, 82, 70-83.

Cagno, E., Trianni, A., Abeelen, C., Worrell, E., \& Miggiano, F. (2015). Barriers and drivers for energy efficiency: Different perspectives from an exploratory study in the Netherlands. Energy Conversion and Management, 102, 26-38.

Cagno, E., Worrell, E., Trianni, A., \& Pugliese, G. (2013). A novel approach for barriers to industrial energy efficiency. Renewable and Sustainable Energy Reviews, 19, 290-308.

CEATI. (2007). Compressed air - Energy efficiency reference guide. CEA Technologies Inc. (CEATI).

Cooremans, C. (2012). Investment in energy efficiency: Do the characteristics of investments matter? Energy Efficiency, 5, 497-518.

De Groot, H., Verhoef, E., \& Nijkamp, P. (2001). Energy saving by firms: Decision-making, barriers and policies. Energy Economy, 23, 717-740.

DOE. (2003). Improving compressed air system performance: A sourcebook for industry; U.S. Department of Energy (DOE), Energy Efficiency and Renewable Energy, Washington, D.C. DOE/GO-102003-1822.

https://www1.eere.energy.gov/manufacturing/tech_assistance/pdfs/compressed_air_s ourcebook.pdf Assessed 5 March 2016.

EC. (2011). Communication from the Commission to the European Parliament, the Council, the European Economic and Social Committee and the Committee of the Regions. Energy Efficiency Plan 2011. Brussels: European Commission.

Finman, H., \& J. A. Laitner. (2001). Industry, energy efficiency and productivity improvements. Proceedings of the 2001 Summer Study on Energy Efficiency in Industry, pp. 561-570.

Fleiter, T., Hirzel, S., \& Worrell, E. (2012). The characteristics of energy-efficiency measures - A neglected dimension. Energy Policy, 51, 502-513.

Hall, N. P., \& Roth, J. A. (2003). Non-energy benefits from commercial and industrial energy efficiency programs: Energy efficiency may not be the best story. Proceedings of the 2003 International Energy Program Evaluation Conference, pp. 689-702.

Hanna, J. B., \& Baker, M. (2000). Making performance analysis business-as-usual in the industrial compressed-air market. Proceedings of the 2000 Summer Study on Energy Efficiency in Buildings, 6, 6145-6155.

Harris, J., Anderson, J., \& Shafron, W. (2000). Investment in energy efficiency: A survey of Australian firms. Energy Policy, 28, 867-876. 
Hasanbeigi, A., Menke, C., \& du Pont, P. (2010). Barriers to energy efficiency improvement and decision-making behavior in Thai industry. Energy Efficiency, 3, 33-52.

IEA. (2012). Spreading the Net: The multiple benefits of energy efficiency improvements. Insights Series 2012. Paris: International Energy Agency.

IPCC. (2014). Impacts, adaptation and vulnerability. Intergovernmental panel on climate change. Fifth assessment report, 2014.

Johansson, P-E., Thollander, P., \& Moshfegh, B. (2011). Towards increased energy efficiency in industry - A manager's perspective. Proceedings of World Energy Renewable Congress 2011, Sweden, 1644-1651.

Kvale, S., \& Brinkmann, S. (2009). Den kvalitativa forskningsintervjun. Lund, Sweden: Studentlitteratur.

Laitner, J. A., Ruth, M. B., \& Worrell, E. (2001). Incorporating the productivity benefits into the assessment of cost effective energy savings potential using conservation supply curves. Proceedings of the 2001 Summer Study on Energy Efficiency in Industry, pp. 597-608.

Lee, K-H. (2015). Drivers and barriers to energy efficiency management for sustainable development. Sustainable Development, 23, 16-25.

Lilly, P., \& Pearson D. (1999). Determining the full value of industrial efficiency programs. Proceedings ACEEE Summer Study on Energy Efficiency in Industry, pp. 349-362.

Lung, R. B., McKane, A., Leach R., \& Marsh D. (2005). Ancillary savings and production benefits in the evaluation of industrial energy efficiency measures. Proceedings of the ACEEE Summer Study on Energy Efficiency in Industry, 104-114.

Marshall, R. (2012). Optimization of single-unit compressed air systems. Energy Engineering: Journal of the Association of Energy Engineering, 109(1), 10-35.

Meath, C., Linnenluecke, M., \& Griffiths, A. (2016). Barriers and motivators to the adoption of energy savings measures for small and medium-sized enterprises (SMEs): The case of the ClimateSmart Business Cluster program. Journal of Cleaner Production, 112, 3597-3604.

Neale, J. R., \& Kamp, P. J. J. (2010). Compressed air system best practice programmes: What needs to change to secure long-term energy savings for New Zealand? Energy Policy, 37, 34003408.

Nehler, T., \& Rasmussen, J. (2016). How do firms consider non-energy benefits? Empirical findings on energy-efficiency investments in Swedish industry. Journal of Cleaner Production, 113, 472-482.

Paramonova, S., Thollander, P., \& Ottosson, M. (2015). Quantifying the extended energy efficiency gap - evidence from Swedish electricity-intensive industries. Renewable and Sustainable Energy Reviews 51, 472-483.

Pye, M., \& McKane, A. (2000). Making a stronger case for industrial energy efficiency by quantifying non-energy benefits. Resources, Conservation and Recycling, 28, 171-183.

Rohdin, P., \& Thollander, P. (2006). Barriers to and driving forces for energy efficiency in the nonenergy intensive manufacturing industry in Sweden. Energy, 31, 1836-1844.

Rosenqvist, J., Thollander, P., Rohdin, P., \& Söderström, M. (2012). Industrial energy auditing for increased sustainability - Methodology and measurements. Book chapter in Sustainable Energy - Recent Research. InTech Publisher.

Rohdin, P., Thollander, P., \& Solding, P. (2007). Barriers to and drivers for energy efficiency in the Swedish foundry industry. Energy Policy, 35(1), 672-677.

Saidur, R., Rahim, N. A., \& Hasanuzzaman, M. (2010). A review on compressed-air energy use and energy savings. Renewable and Sustainable Energy Reviews, 14, 1135-1153.

Sardianou, E. (2008). Barriers to industrial energy efficiency investments in Greece. Journal of Cleaner Production, 13, 1416-1423.

Skumatz, L. A., Dickerson, C. A., \& Coates, B. (2000). Non-energy benefits in the residential and non-residential sectors - Innovative measurements and results for participant benefits. Proceedings of the ACEEE Summer Study on Energy Efficiency in Buildings, 8, 353-364.

Sorrell, S., O'Malley, E., Schleich, J., \& Scott, S. (2004). The economics of energy efficiency. Cheltenham, UK: Edward Elgar Publishing. 
Sorrell, S., Schleich, J., Scott, S., O’Malley, E., Trace, F., Boede, E., Ostertag, K., \& Radgen, P. (2000). Reducing barriers to energy efficiency in public and private organizations. http://www.sussex.ac.uk/Units/spru/publications/reports/barriers/finaltoc.pdf Accessed 21 March 2017.

Söderström, M. (1996). Industrial electricity use characterized by unit processes. A tool for analysis and forecasting. Proceedings of the UIE XIII Congress on Electricity Applications, Birmingham, pp. 77-85.

Söderström, M., Carlsson, P., \& Hall, O. (1994). Enhetsprocesser - Ett sätt att strukturera industrins energianvändning. Linköping, Tech. rep., Linköping University and Sydkraft Konsult.

Thollander, P., \& Ottosson, M. (2008). An energy-efficient Swedish pulp and paper industry Exploring barriers to and driving forces for cost-effective energy efficiency investments. Energy Efficiency, 1(1), 21-34.

Trianni, A., \& Cagno, E. (2012). Dealing with barriers to energy efficiency and SMEs: Some empirical evidences. Energy, 37, 494-504.

Trianni, A., Cagno, E., \& De Donatis, A. (2014). A framework to characterize energy efficiency measures. Applied Energy, 118, 207-220.

Trianni, A., Cagno, E., \& Farné, S. (2016). Barriers, drivers and decision-making process for industrial energy efficiency: A broad study among manufacturing small and medium-sized enterprises. Applied Energy, 162, 1537-1551.

Trianni, A., Cagno, E., Marchesani, F., \& Spallina, G. (2017). Classification of drivers for industrial energy efficiency and their effect on the barriers affecting the investment decision-making process. Energy Efficiency, 10, 199-215.

Venmans, F. (2014). Triggers and barriers to energy efficiency measures in the ceramic, cement and lime sectors. Journal of Cleaner Production, 69, 133-142.

Worrell, E., Laitner, J., Ruth, M., \& Finman, H. (2003). Productivity benefits of industrial energy efficiency measures. Energy, 28(11), 1081-1098.

Yin, R. K. (2009). Case study research: Design and methods (4th ed.). Thousand Oaks, CA: SAGE. 


\section{Appendix A}

\begin{tabular}{|c|c|}
\hline Barriers & Drivers \\
\hline Technology is inappropriate at this site & People with real ambition \\
\hline $\begin{array}{l}\text { Cost of production } \\
\text { disruption/hassle/inconvenience }\end{array}$ & Commitment from top management \\
\hline $\begin{array}{l}\text { Cost of identifying opportunities, analysing cost } \\
\text { effectiveness and tendering }\end{array}$ & Threat of rising energy prices \\
\hline $\begin{array}{l}\text { Cost of staff replacement, retirement and } \\
\text { retraining }\end{array}$ & Long-term energy strategy \\
\hline Possible poor performance of equipment & $\begin{array}{l}\text { Cost reductions resulting from lowered energy } \\
\text { use }\end{array}$ \\
\hline Access to capital & Energy Management System (EMS) \\
\hline Slim organisation & Detailed support from energy experts (helpdesk) \\
\hline Lack of budget funding & Network within the company/group \\
\hline Other priorities for capital investments & $\begin{array}{l}\text { Publicly financed energy audits by energy } \\
\text { consultant }\end{array}$ \\
\hline $\begin{array}{l}\text { Technical risks, such as risk of production } \\
\text { disruptions }\end{array}$ & $\begin{array}{l}\text { Publicly financed energy audits by sector } \\
\text { organisation expert }\end{array}$ \\
\hline Uncertainty regarding the company's future & Energy audit subsidy \\
\hline $\begin{array}{l}\text { Poor information quality regarding energy } \\
\text { efficiency opportunities }\end{array}$ & Demand from owner \\
\hline $\begin{array}{l}\text { Difficulties in obtaining information about the } \\
\text { energy use of purchased equipment }\end{array}$ & Environmental company profile \\
\hline Lack of time or other priorities & Customer questions and demands \\
\hline Lack of technical skills & General energy advice through journal/booklet \\
\hline Lack of staff awareness & $\begin{array}{l}\text { Investment subsidies for energy efficiency } \\
\text { technologies }\end{array}$ \\
\hline $\begin{array}{l}\text { Department/workers not accountable for energy } \\
\text { costs }\end{array}$ & Energy tax \\
\hline $\begin{array}{l}\text { Energy objectives not integrated into operating } \\
\text { maintenance or purchasing procedures }\end{array}$ & Improved working conditions \\
\hline Low priority given to energy management & Voluntary agreements with tax exemption \\
\hline Energy manager lacks influence & Beneficial loans for energy efficiency investments \\
\hline Conflicts of interest within the company & Pressure from different environmental NGOs \\
\hline Lack of sub-metering & International competition \\
\hline \multirow[t]{3}{*}{ Long decision chains } & General energy advice through seminars \\
\hline & Local authority energy consultancy \\
\hline & $\begin{array}{l}\text { Energy efficiency requirements due to national } \\
\text { environmental codes }\end{array}$ \\
\hline
\end{tabular}




\begin{tabular}{|l|l|}
\hline & Environmental Management System \\
\hline & $\begin{array}{l}\text { Your municipality being part of an energy/climate } \\
\text { efficiency program }\end{array}$ \\
\hline & $\begin{array}{l}\text { Information and support through the sector } \\
\text { organisation }\end{array}$ \\
\hline & Any emissions-related tax \\
\hline & $\begin{array}{l}\text { ESCOs responsible for operation and maintenance } \\
\text { of the buildings }\end{array}$ \\
\hline & The public sector as a role model \\
\hline & European Emissions Trading Scheme (EU ETS) \\
\hline & Network within the sector \\
\hline & Third-party financing \\
\hline
\end{tabular}

\begin{tabular}{|c|l|}
\hline \multicolumn{2}{|c|}{ NEBs tested in the questionnaire distributed to energy auditors } \\
\hline $\mathbf{1}$ & Increased production \\
\hline $\mathbf{2}$ & Improved product quality \\
\hline $\mathbf{3}$ & More reliable production (e.g. reduced number of stoppages) \\
\hline $\mathbf{4}$ & Increased lifetime of equipment \\
\hline $\mathbf{5}$ & Shorter cycle times for processes \\
\hline $\mathbf{6}$ & Reduced consumption of production material/raw material \\
\hline $\mathbf{7}$ & Reduced maintenance \\
\hline $\mathbf{8}$ & Reduced labour requirements \\
\hline $\mathbf{9}$ & Reduced cooling requirements* \\
\hline $\mathbf{1 0}$ & Safer working environment \\
\hline $\mathbf{1 1}$ & Reduced noise \\
\hline $\mathbf{1 2}$ & Improved air quality \\
\hline $\mathbf{1 3}$ & Improved temperature control* \\
\hline $\mathbf{1 4}$ & Reduction of wastewater \\
\hline $\mathbf{1 5}$ & Reduction of hazardous waste \\
\hline $\mathbf{1 6}$ & Reduced waste (other waste) \\
\hline $\mathbf{1 7}$ & Reduced emissions of e.g. CO, $\mathrm{CO}_{2}, \mathrm{NO}_{x}, \mathrm{SO}_{\mathrm{x}}$ \\
\hline $\mathbf{1 8}$ & Reduced emission of e.g. ash, dust \\
\hline $\mathbf{1 9}$ & Improved corporate image \\
\hline $\mathbf{2 0}$ & Increased employee morale \\
\hline $\mathbf{2 1}$ & $\begin{array}{l}\text { Capital avoidance (for instance, a company cancels or delays its plans to acquire new equipment } \\
\text { due to implementation of an energy-saving project) }\end{array}$ \\
\hline
\end{tabular}

* Reduced cooling requirements and improved temperature control might also be considered as energy benefits with respect to energy efficiency improvements in CAS. For instance, intake of outside instead of indoor air will lower cooling requirements, and in a CAS, this implies a lowered energy demand. 